\title{
Expression of Breast Cancer-Related Epitopes Targeting the IGF-1 Receptor in Chimeric Human Parvovirus B19 Virus-Like Particles
}

\author{
Jorge Alberto Salazar-González ${ }^{1}$ Alail Antonio Ruiz-Cruz ${ }^{1}$. Ismael Bustos-Jaimes ${ }^{2} \cdot$ Leticia Moreno-Fierros $^{1}$
}

Published online: 17 July 2019

○) Springer Science+Business Media, LLC, part of Springer Nature 2019

\begin{abstract}
Breast cancer is a worldwide health problem, and the complexity of the disease, as well as the lack of treatment specificity, generates an urgent need for developing prophylactic and therapeutic measures. Searching for novel epitope-based approaches able to induce tumour immunity, we designed virus-like particles (VLPs) derived from Human parvovirus B19 assembled of chimeric VP2 proteins displaying two epitopes from the insulin-like growth factor-1 receptor (IGF-1R). Here, we present the generation of two chimeric VP2s that retain the stability, solubility and conditions of purification and assembly of the native VP2. We generated versatile chimeric multiepitope anti-cancer vaccine candidates, which prevented and delayed tumour growth when used in a prophylactic scheme of 4 weekly immunizations prior to $4 \mathrm{~T} 1$ cell inoculation in female BALB/c mice. The presence of specific antibodies against the displayed epitopes suggests their participation in the protective effect; in contrast, no significant proliferative T-cell responses were recorded following stimulation by specific epitopes. The results comprise an approach whereby fusing desired epitopes from cancer to the N-terminus of B19 VP2 protein can generate a library of chimeric VP2-desired epitopes for further assembly in a designed and personalized epitope delivery system.
\end{abstract}

Keywords Breast cancer $\cdot$ Vaccine $\cdot$ VLPs $\cdot$ Multiepitope $\cdot$ IGF-1R

\section{Introduction}

Breast cancer represents an important health problem of which the incidence is increasing worldwide. The most common therapies against breast cancer are surgery, chemotherapy and radiotherapy. However, these have two major limitations: their lack of specificity and/or their ineffectiveness in controlling minimal residual disease $[1,2]$. It is recognized that the immune system plays a fundamental role in the surveillance and destruction of malignant cells, preventing the formation of tumours. However, cancer cells

Jorge Alberto Salazar-González

jorge_fhkh@hotmail.com

$\bowtie$ Leticia Moreno-Fierros

lemofi@unam.mx

1 Laboratorio de Inmunidad en Mucosas, Unidad de Biomedicina, Facultad de Estudios Superiores Iztacala, Universidad Nacional Autónoma de México, Avenida de los Barrios 1, Los Reyes Iztacala, 54090 Tlalnepantla, Mexico

2 Departamento de Bioquímica, Facultad de Medicina, Universidad Nacional Autónoma de México, Av. Universidad 3000, C.U., 04510 Mexico City, Mexico also have various mechanisms to evade the immune system [2]. Against this background, immunotherapies directed at tumour-associated antigens (TAAs) have been explored as therapeutic targets to eliminate cancer cells by employing strategies of either passive immunity (i.e. administration of monoclonal antibodies) or active immunity (i.e. activation of the host $\mathrm{T}$ or $\mathrm{B}$ lymphocyte immune response by specific immunogens).

Although the landscape of characterization of TAAs is promising, there is a need to develop strategies aimed at various TAAs as targets for therapy, considering that the experience achieved so far indicates that resistance to immunotherapy is often present. For example, in the case of trastuzumab, most patients who respond to treatment initially experience disease progression during the first year [3]. Therefore, in the field of immunotherapy against cancer, it is essential to consider the development of strategies directed against different epitopes of the same TAA and even several TAAs in order to generate synergistic responses, both cellular and humoral, able to improve treatment effectiveness.

Among the TAAs described, it has been proved that the insulin-like growth factor-1 receptor (IGF-1R) is overexpressed in at least $50 \%$ of breast cancers [4]. It participates 
in cell growth and also plays an important role in the metastatic process by regulating cell migration, invasion and angiogenesis. IGF-1R has been associated with angiogenesis in several tumour types, since its activation increases the expression of vascular endothelial growth factor (VEGF). In patients with metastatic breast cancer, an elevated level of serum IGF-1 and VEGF has been observed, compared with controls and patients without metastatic disease [5]. Inhibition of IGF-1R in several tumour lines produced a decrease in VEGF expression, angiogenesis and metastasis [6, 7]. Bioinformatic reports identifying relevant epitopes of IGF1R revealed the P8 (RQPQDGYLYRHNYCSK), a B-cell linear epitope which is part of the extracellular region of the receptor, specifically in the fibronectin type III domain FnIII, and the 249 (GDLTNRCTMEEKPMEK), a T-cell epitope, also from the FnIII domain, which binds both major histocompatibility complexes (MHC) class I and II. It is worth mentioning that these two epitopes have no identity with the insulin receptor $[8,9]$.

One of the limitations of the use peptides as epitope-based vaccines is their lack of immunogenicity, which might be solved by the use of either appropriate adjuvants or antigen delivery systems. The use of recombinant chimeric proteins to carry epitopes has been explored as an emerging field of action with great potential. However, the design of this type of vaccines faces particular challenges, such as achieving a chimeric protein that (1) is adequately expressed in an appropriate host, (2) retains the immunogenic properties of the epitopes and (3) is captured and processed appropriately by the antigen-presenting cells, which allows the induction of the desired immune responses in terms of polarization and potency, particularly in tumour tissues [10].

Virus-like particles (VLPs), nanoparticles comprised of highly ordered repetitive structures able to form macromolecular assemblies of viral proteins without carrying infectious genomic material, are promising carrier systems. There are plenty of reports of the potential for impact in the VLP-derived vaccine development field [11-13]. It is well known that VLPs are potent inducers of B-cell responses and are also able to induce cytotoxic T-cell responses [14, 15]. VLPs can stimulate both innate and adaptive immune responses, aided by their particulate structure, which favours uptake by antigen-presenting cells [16]. Thus, they combine both safety and the potency to elicit a strong immune response $[17,18]$ due to their size, shape and surface, where they display epitopes in a dense repetitive array $[19,20]$.

Herein, we achieved the expression of self-assembled VLPs from the Human parvovirus B19 (B19V) derived from the recombinant VP2 protein expressed in Escherichia coli [21] fused to 2 epitopes of IGF-1R in different configurations, and the cellular and humoral responses of chimeric VLPs were determined to assess the most efficient vaccine prototype configuration against breast cancer.

These recombinant chimeras of B19V VP2 fused to the 249 and P8 epitopes were expressed and retained their self-assembly capacity to form VLPs. Each chimera can be assembled alone or as a mixture to create a multiepitope VLP approach. These hybrid VLPs have enormous potential as a versatile vaccine prototype that can be used as immunotherapy against breast cancer and other cancer types, as the results show they are able to delay tumour growth in a murine model of breast cancer.

\section{Materials and Methods}

\section{Overall Strategy}

The strategy of expression and assembly of the VLPs, summarized in Fig. 1, consisted of generating a fusion between
Fig. 1 Expression strategy and possible assembly conformations for IGF-1R epitopes-VP2 VLPs. Each IGF-1R epitope, 249 and P8 was fused separately into the Human parvovirus B19 VP2 (a), to create a collection of several subunits of chimeric VP2. VLPs self-assembly can produce a versatile variety of configurations: a full assembly from a single epitope (b). Under this configuration, we can express any "Epitope" as E and create two or more different epitopes in a single assembled VLP to achieve a multiepitope versatile configuration displaying each epitope in the surface of the VLPs (c, d)

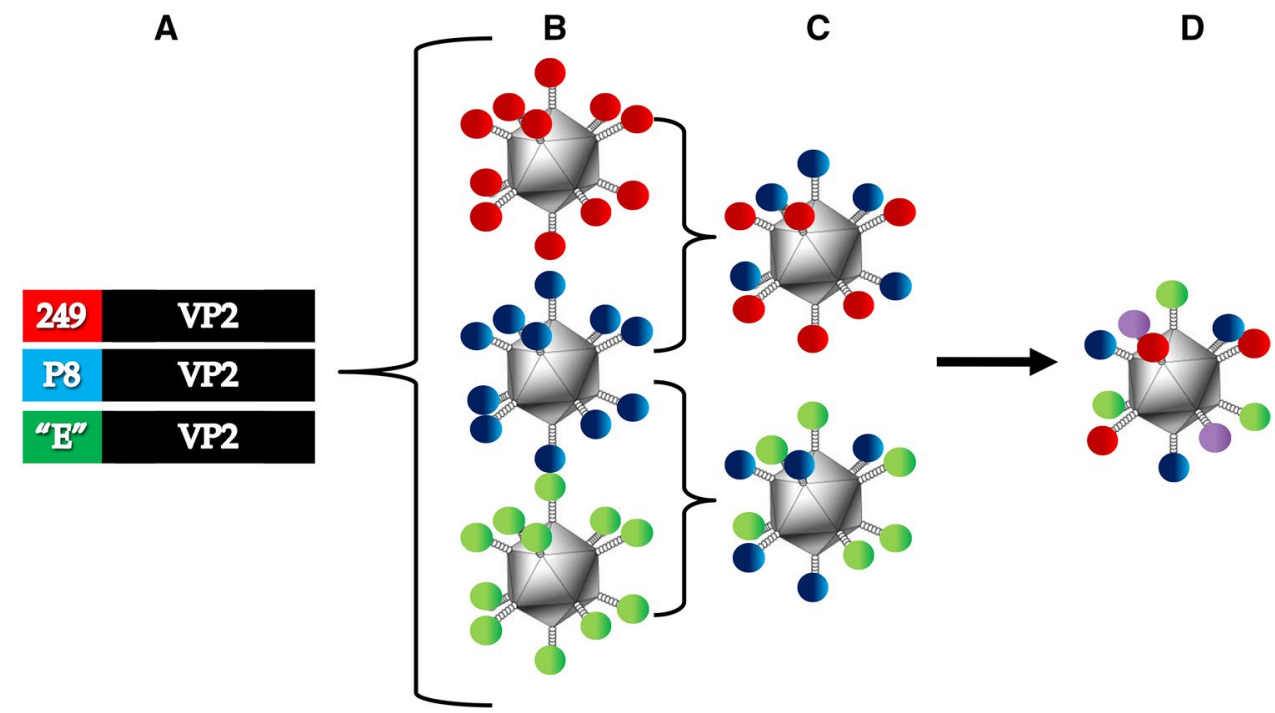


the N-terminal part of the viral protein VP2 of B19V and each of two different epitopes from IGF-1R, 249 and P8, to create a collection of several chimeric VP2 subunits. The self-assembly of VLP can produce different configurations: a complete assembly of a single epitope or two or more different epitopes in a single assembled VLP, to achieve a versatile multiepitope configuration showing each epitope on the surface of the VLP. In this report, we assembled 3 populations of chimeric VLPs consisting of (i) 100\% VP2-P8, (ii) $100 \%$ VP2-249 and (iii) VLPs formed with 50\% VP2-P8 and $50 \%$ VP2-249 in a 1:1 ratio.

\section{Gene Design and Molecular Cloning}

Two synthetic genes of IGF-1R encoding the 249 epitope (GDLTNRCTMEEKPMEK) and P8 epitope (RQPQDGYLYRHNYCSK) were flanked by NdeI and BamHI restriction sites. The codon-optimized gene for expression in E. coli was defined and synthesized by GenScript Co. (NJ, USA) in the pUC57 vector.

A pET22+ vector expressing a chimera of B19V VP2 with NdeI and Bam HI restriction sites in the 5' ATG [22] was used to clone the IGF1-R epitopes using standard cloning protocols to create the expression vectors pET22+ VP2246 and pET22 + VP2-P8, and then transformed into E. coli strain BL21 (DE3) by employing a heat-shock transformation protocol. PCR amplifications were performed to confirm the identity of the cloned fragment with internal specific forward PCR primers: 249 (5'TGGCAACGGTTGGTC AGGTCA) and P8 (5'GTGACGATACAGGTAACCGTC TTGC) and a reverse primer Pet22+ (5'GATCTCGATCCC GCGAAATTAA) under standard PCR conditions.

\section{VP2 Detection}

The integrity of the chimeric protein was assessed by western blot analysis. Protein extracts were obtained by resuspension of the bacterial pellet in reducing loading buffer. Samples were denatured by boiling for $10 \mathrm{~min}$ at $95{ }^{\circ} \mathrm{C}$. SDS-PAGE was performed in $10 \%$ acrylamide gels under denaturing conditions. The gel was blotted onto BioRad PVDF membrane. After blocking in TBS-T containing 5\% fat-free milk, blots were incubated for $2 \mathrm{~h}$ at room temperature with anti-sera against VP2 at 1:10,000 dilution and a secondary anti-rabbit antibody IgG-IRDye800 (Dil 1:5000), and incubated for $2 \mathrm{~h}$ at room temperature. Antibody binding was visualized with an ODYSSEY (LI-COR, NE, USA) scanner at $800 \mathrm{~nm}$.

\section{Selection of Clones by Double Selection}

Expression of VP2-249, VP2-P8 and VP2 was carried out in $5 \mathrm{~mL}$ of liquid LB medium (Tryptone $10 \mathrm{~g} / \mathrm{L}$, yeast extract $5 \mathrm{~g} / \mathrm{L}, \mathrm{NaCl} 10 \mathrm{~g} / \mathrm{L})$ supplemented with Ampicillin $100 \mathrm{mg} / \mathrm{L}$. Then, $25 \mu \mathrm{M}$ of Isopropyl $\beta$-D-1thiogalactopyranoside (IPTG) was added as an inducer. Cell growth was achieved by incubating the cells at $30{ }^{\circ} \mathrm{C}$ for $16 \mathrm{~h}$ with shaking at $200 \mathrm{RPM}$. After this, the expression of clones was analysed by SDS-PAGE to select those with high expression. Selected clones were tested a second time under the same scheme.

\section{Expression of VP2 and Chimeric Proteins}

For larger scale expression, selected colonies of VP2-249, VP2-P8 and VP2 were cultured in $200 \mathrm{~mL}$ of a mixed medium: $100 \mathrm{~mL}$ of $\mathrm{LB}+100 \mathrm{~mL}$ Terrific Broth (TB) (Tryptone $12 \mathrm{~g} / \mathrm{L}$, Yeast Extract $24 \mathrm{~g} / \mathrm{L}, \mathrm{KH}_{2} \mathrm{PO}_{4} 0.17 \mathrm{M}$ and $\mathrm{K}_{2} \mathrm{HPO}_{4} 0.72 \mathrm{M}$ ), for $16 \mathrm{~h}$ at $30{ }^{\circ} \mathrm{C}$, with shaking at 200 RPM.

Cells were harvested by centrifugation at $5000 \mathrm{RPM}$ at $4{ }^{\circ} \mathrm{C}$ for $20 \mathrm{~min}$. The cell pellets were resuspended in a lysis buffer $\left(0.3 \mathrm{M} \mathrm{NaCl}, 50 \mathrm{mM} \mathrm{NaH}_{2} \mathrm{PO}_{4}, \mathrm{pH} 6.3\right)$ and then lysed by sonication using $10 \mathrm{~s}$ pulses with $10 \mathrm{~s}$ off $(28 \%$ amplitude) for $15 \mathrm{~min}$ in an ice-water bath. Lysed cells were centrifuged at $8000 \mathrm{RPM}$ for $10 \mathrm{~min}$ at $4{ }^{\circ} \mathrm{C}$, the pellet was resuspended in $10 \mathrm{~mL}$ of lysis buffer and a sonic pulse of $40 \mathrm{~s}$ was given. The inclusion bodies were collected by centrifugation at $8000 \mathrm{RPM}$ for $20 \mathrm{~min}$ at $4{ }^{\circ} \mathrm{C}$ followed by 3 washes with washing buffer $\left(50 \mathrm{mM} \mathrm{NaH}{ }_{2} \mathrm{PO}_{4}, \mathrm{pH}\right.$ 6.3, 0.3 M NaCl, 2\% Triton X-100, $3 \mathrm{M}$ urea), and the 40-s pulse cycle and centrifugation were repeated 2 times. Subsequently, inclusion bodies were resuspended in washing buffer supplemented with $3 \mathrm{mM}$ DTT and finally with lysis buffer to eliminate Triton X-100 and urea. The remaining pellet was solubilized in $20 \mathrm{~mL}$ of lysis buffer with $2 \mathrm{mM}$ DTT and guanidine hydrochloride ( $\mathrm{GdnHCl}, 6 \mathrm{M}, \mathrm{pH}$ 6.3). Finally, the inclusion bodies were left in solubilization buffer at $37^{\circ} \mathrm{C}$ at $10 \mathrm{RPM}$ overnight.

\section{Purification of the VP2-249 and VP2-p8 Chimeras and VP2 by IMAC}

To facilitate purification, VP2 and the chimeras have a 6xHis-tag at their C-termini. The purification protocol for VP2 and its derivative chimeras was also standardized under denaturing conditions, and immobilized metal affinity chromatography (IMAC) was performed on a column of $2 \mathrm{~mL}$ nickel resin. The column was equilibrated with 4 volumes of equilibrium buffer (PBS, $6 \mathrm{M} \mathrm{GdnHCl,} 10 \mathrm{mM}$ imidazole), then the protein was loaded on the column for subsequent washing with 8 volumes of washing buffer (PBS, $\mathrm{GdnHCl}$ $6 \mathrm{M}, 50 \mathrm{mM}$ imidazole). Proteins were eluted with $6 \mathrm{~mL}$ Elution Buffer (PBS, $6 \mathrm{M} \mathrm{GdnHCl}$ and $250 \mathrm{mM}$ imidazole) in $1 \mathrm{~mL}$ fractions. Subsequently, each of the eluted fractions, as well as unbound protein fractions and pre-elution void 
volume, was analysed by SDS-PAGE and visualized with Coomassie blue staining.

\section{VLPs Quantification, Assembly and Characterization}

Eluted fractions from IMAC purification were concentrated by centrifugation in filtration units (Millipore, MA, USA) with a MWCO of $30 \mathrm{kDa}$ and quantified by the Bradford method against known concentrations of bovine serum albu$\min ($ BSA) $(100 \mathrm{ng}-4 \mu \mathrm{g})$.

VLP assembly was carried out by dialysis of $1 \mathrm{~mL}$ of the proteins $(0.750 \mathrm{mg} / \mathrm{mL}$ in Solubilization Buffer) against $50 \mathrm{~mL}$ of PBS pH 7.4 supplemented with $0.25 \mathrm{M}$ of L-Arginine, at $4{ }^{\circ} \mathrm{C}$, changing the buffer every $12 \mathrm{~h}$ for $72 \mathrm{~h}$. For the assembly of hybrid particles, the protein concentrations of both chimeras, VP2-249 and VP2-P8, were adjusted to $0.375 \mathrm{mg} / \mathrm{mL}$ each.

After assembly, the particle size was characterized by dynamic light scattering (DLS) in a Zetasizer $\mu \mathrm{V}$ (Malvern, UK) equipped with a photodiode laser $(830 \mathrm{~nm})$. Samples were filtered through $0.22-\mu \mathrm{m}$ polyvinylidene fluoride (PVDF) syringe filters (Millipore, MA, USA). The measurements for each sample were averaged over 10 sets of 10 measurements per run at $20^{\circ} \mathrm{C}$.

\section{Immunization Protocol}

The immunogenicity of chimeric VLPs was assessed in 8 -week-old female BALB/c mice. Test animals were maintained under standard laboratory conditions with free access to food and water following the procedures indicated by the Federal Regulation for Animal Experimentation and Care (SAGARPA, NOM-062-ZOO-1999, México), approved by the Institutional Animal Care and Use Committee.

Test animals were randomly selected to form the following test groups: (i) control group, $\mathrm{PBS}+0.25 \mathrm{M} \mathrm{Arg}(n=4)$; (ii) native VP2 VLPs $(n=2)$; (iii) chimeric VP2-249 $(n=2)$; (iv) chimeric VP2-P8 $(n=2)$; and v) VP2-249 + VP2-P8 in a 1:1 ratio $(n=2)$. Each group was administered $100 \mu \mathrm{g}$ of each VLP intraperitoneally (IP) and $25 \mu \mathrm{g}$ subcutaneously (SC) above the left inguinal mammary gland. The control group was administered $100 \mu \mathrm{L}$ and $25 \mu \mathrm{L}$ of PBS $+0.25 \mathrm{M}$ Arg IP and SC, respectively.

At day 29, serum samples were collected from blood extracted via tail vein sampling and stored at $-70{ }^{\circ} \mathrm{C}$ until antibody assessment. ELISA assays were performed to determine the presence of specific antibodies in mouse sera, so reactivity against synthetic peptides carrying the target epitopes P8 or 249 was assessed. Assay plates were coated with P8 or 249 synthetic peptides (GenScript Co. (NJ, USA), $5 \mu \mathrm{g} / 100 \mu \mathrm{l}$ per well) overnight at $4{ }^{\circ} \mathrm{C}$ and subsequently blocked with $5 \%$ fat-free dry milk for $2 \mathrm{~h}$ at $25{ }^{\circ} \mathrm{C}$. Plates were further incubated overnight at $4{ }^{\circ} \mathrm{C}$ with serial dilutions of mouse sera (1:10 dilution). The secondary antibody, goat horseradish peroxidase-conjugated anti-mouse $\mathrm{IgG}$, was added (1:2000 dilution), and the plates were incubated for $1 \mathrm{~h}$ at $25^{\circ} \mathrm{C}$. After washing, the substrate 2,2'-azino-bis(3ethylbenzothiazoline-6-sulfonic) (ABTS) with $1 \mathrm{mM}$ of $\mathrm{H}_{2} \mathrm{O}_{2}$ was added. The $\mathrm{OD}$ at $405 \mathrm{~nm}$ was measured during 60 min with an ELISA reader.

\section{T1 Cell Culture}

The 4T1 mouse mammary tumour cell line (ATCC, Cat\# CRL-2539, RRID:CVCL_0125, VA, USA) was donated by Dr Pedro Ostoa. Cells were cultured in $15 \mathrm{~mL}$ of Roswell Park Memorial Institute 1640 (RPMI-1640) medium supplement with $10 \%$ foetal calf serum (FCS) and antibiotics (100 units $/ \mathrm{mL}$ penicillin and $100 \mu \mathrm{g} / \mathrm{mL}$ streptomycin) at $37^{\circ} \mathrm{C}$ in a humidified atmosphere containing $5 \% \mathrm{CO}_{2}$, in $75 \mathrm{~cm}^{2}$ polystyrene culture flasks following $2-3$ subcultures per week until the culture reached $80 \%$ confluence. To harvest 4T1 tumour cells, culture medium from the tissue culture flask was discarded, the cells were washed with 5-7 mL serum-free medium, $10 \mathrm{~mL}$ Versene solution $(0.48 \mathrm{mM})$ was added and the flask was incubated at $37^{\circ} \mathrm{C}$ for $8 \mathrm{~min}$. Detached cells were transferred to $15-\mathrm{mL}$ conical tubes prior to centrifugation for $10 \mathrm{~min}$ at $1200 \mathrm{rpm}$ at $4{ }^{\circ} \mathrm{C}$. The supernatant was discarded and the pellet resuspended in serumfree RPMI. The cell concentration was determined using a Neubauer chamber and adjusted with serum-free RPMI to $1 \times 10^{6}$ cells per $\mathrm{mL}$.

\section{Tumour Induction with 4T1 Cells in BALB/c Mice}

At the fourth week post immunization, mice were injected with $30004 \mathrm{~T} 1$ cells into the mammary fat pads. Tumour growth was monitored daily starting at the day when tumours became palpable. Tumour growth was evaluated by measuring tumour diameters twice weekly, and the tumour volume was calculated as length $\times$ width $^{2} \times 0.52$ [23]. Mice were euthanized by cervical dislocation 30 days after cell inoculation.

\section{Proliferation Assay}

Spleens from control and immunized mice were harvested and disaggregated under sterile conditions, after lysis of erythrocytes, leucocytes were filtered and resuspended into complete RPMI medium supplemented with FCS to be labelled with $5 \mathrm{mM}$ Carboxyfluorescein succinimidyl ester (CFSE), according to the manufacturer's instructions (BioLegend, CA, USA). CFSE-Labelled splenic cells, $4 \times 10^{6}$ cells per well, were incubated in the presence of $10 \mu \mathrm{g} / \mathrm{mL}$ of P8 or 249 synthetic peptides, native VP2 or Cry1 Ac toxin as a proliferation control. After $72 \mathrm{~h}$ of incubation, cells were 
washed and stained with anti-CD3 APC, anti-CD4 Cy5PE and anti-CD8 PE, followed by flow cytometry analysis of 50,000 total events using FlowJo software (BD Biosciences, $\mathrm{CA}, \mathrm{USA}$ ) after gating on the $\mathrm{CD} 3+$ population.

\section{Statistical Analysis}

Data are presented as averages \pm SD and were analysed by two-way ANOVA when comparing more than two groups. Results were considered to be statistically significant at $P<0.05$. All statistical analyses were conducted using GraphPad Prism 6.

\section{Results}

\section{Generation of pET22 + VP2-249 and pET22 + VP2-P8}

Commercial pUC57 vectors carrying epitopes 249 and P8 were double digested with $N d e \mathrm{I} / \mathrm{BamHI}$ as well as the pET22+ vector carrying a modified ORF from the B19VVP2 protein (pET22 + VP2) [22] expression vector. After standard ligation procedures in a 5:1 insert/vector molar ratio (100 ng total) and transformation by using a heat-shock protocol, a series of colonies was obtained for each construct. Three colonies for each construct were selected to verify correct cloning by means of PCR. Figure 2 shows the positive PCR amplifications for both epitopes confirming the insertion of the epitope into the vector pET22 + VP2 (amplicon $1350 \mathrm{bp}$ ). For further experiments, clone 1 was selected.

\section{Expression and Purification of Chimeric VP2 Proteins Fused to IGF-1R Epitopes}

To establish the identity of chimeric proteins, western blot analysis with specific antibodies against VP2 from parvovirus B19V was performed. At the same time, this technique revealed differences in the molecular weights of chimeric proteins and VP2. Protein expression was induced with IPTG $(25 \mu \mathrm{M})$ in liquid LB medium supplemented with $100 \mathrm{mg} / \mathrm{L}$ of ampicillin. The procedure consisted of standard western blot conditions with a primary antibody against VP2 produced in rabbit (Dil 1:10,000) and a secondary anti-rabbit antibody IgG-IRDye800 (Dil 1:5000). Figure 3 shows both chimeric VP2-carrying epitopes 249 and P8 as well as VP2 before induction with IPTG and after $16 \mathrm{~h}$ of induction with IPTG at $30{ }^{\circ} \mathrm{C}$. The specific fluorescence of the anti-VP2 antibody confirms the identity of both constructs containing VP2, and the difference between the molecular weights of each of these and VP2 indicates that they contain the fused epitopes of $\sim 64.5 \mathrm{kDa}$ for chimeras VP2-249 and VP2-P8, and $\sim 60 \mathrm{kDa}$ for VP2 (Fig. 3B).

The next step was to establish the colonies that expressed the largest amount of protein, so double-selection trials were performed and analysed by SDS-PAGE. For this, the colonies were plated, and 8 different clones were chosen to undergo a first induction. The one with the highest expression was chosen, subcultured and induced a second time to choose the colonies that showed the highest expression level (Fig. 4). Colony 4 was chosen for expression of VP2-P8 and colony 3 for VP2-249.
Fig. 2 Amplicons generated by PCR. Three putative colonies of each ligation, epitope 249 (a) and epitope P8 (b), were subjected to PCR analysis, and in both cases 1350-bp amplicons were observed. Lanes: $1-3$ putative clones of 249 epitope sequence ligation, 4-6 putative clones of P8 epitope sequence ligation
A

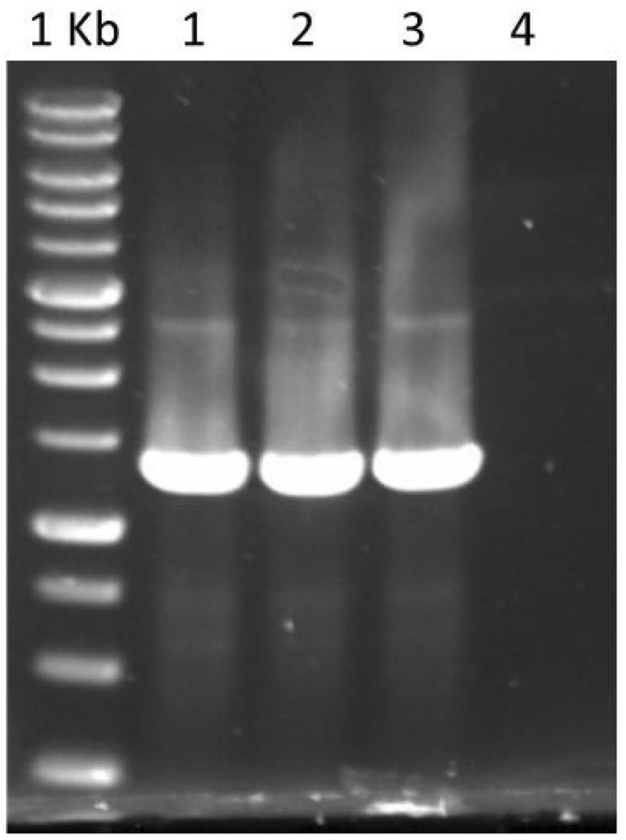

B

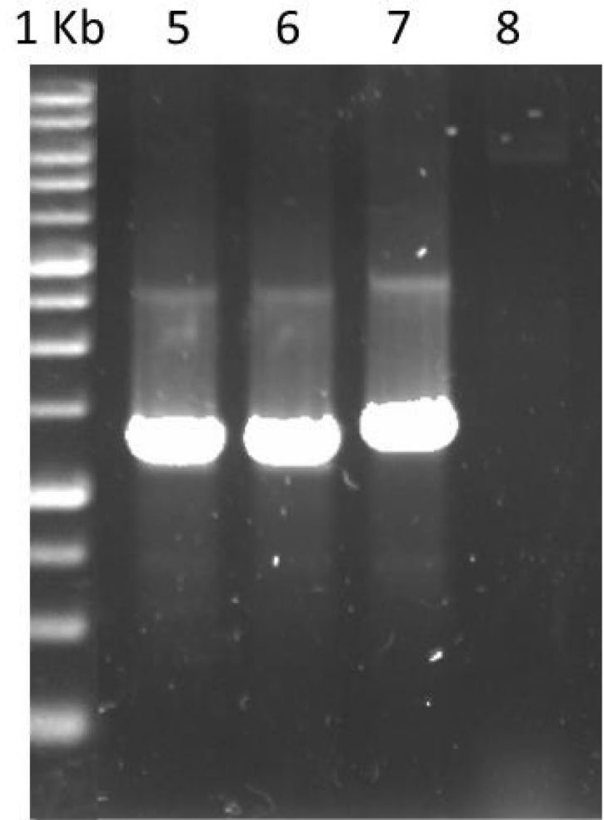




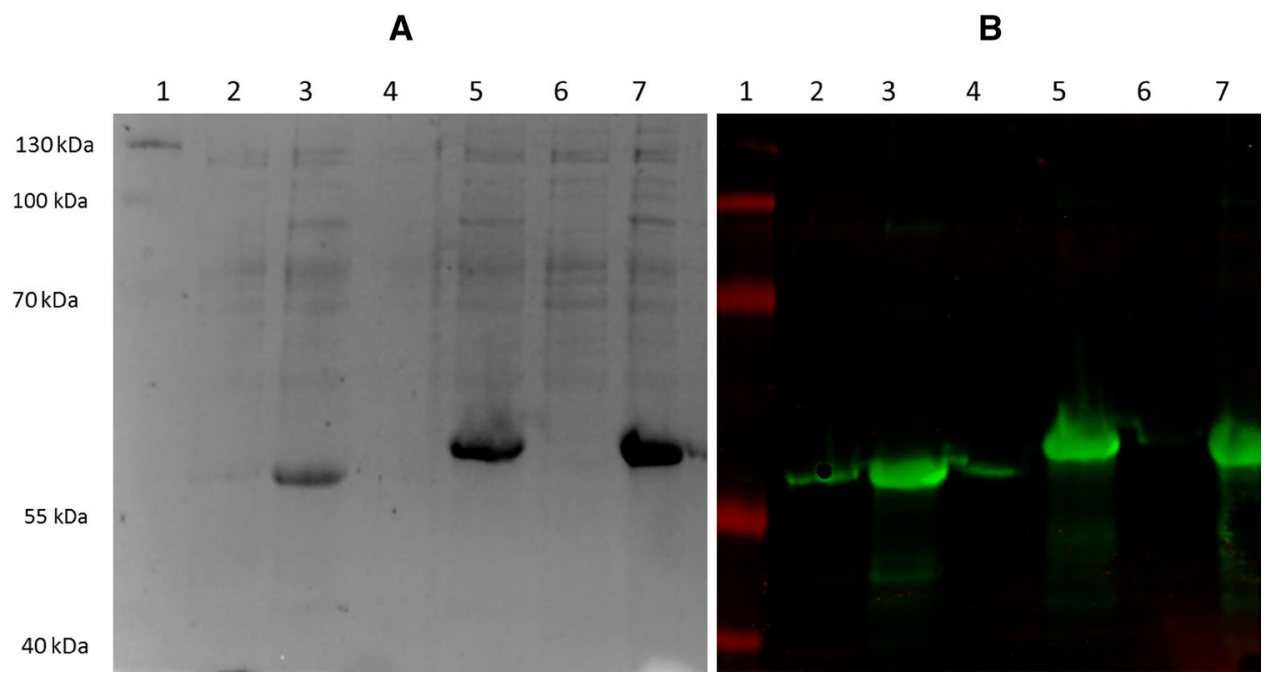

Fig. 3 Pre induction and post induction with IPTG of the expressing colonies of the VP2-249 and VP2-P8 chimeras and Native VP2. Colonies were grown in liquid LB medium and separated for induction with IPTG $(25 \mu \mathrm{M})$ for $16 \mathrm{~h}$ at $30{ }^{\circ} \mathrm{C}$. a Gel electrophoresis stained with Coomassie blue dye. b Western blot with specific antibodies against VP2. In both cases, different sizes were observed as predicted for VP2, VP2-249 and VP2-P8 ( 60 kDa, $\sim 64.5 \mathrm{kDa}$ and $\sim 64.5 \mathrm{kDa}$, respectively). Lanes: 1: Ladder, 2: VP2 pre induction, 3: VP2 post induction, 4: VP2-249 pre induction, 5: VP2-249 post induction, 6: VP2-P8 pre induction and 7: VP2-P8 post induction

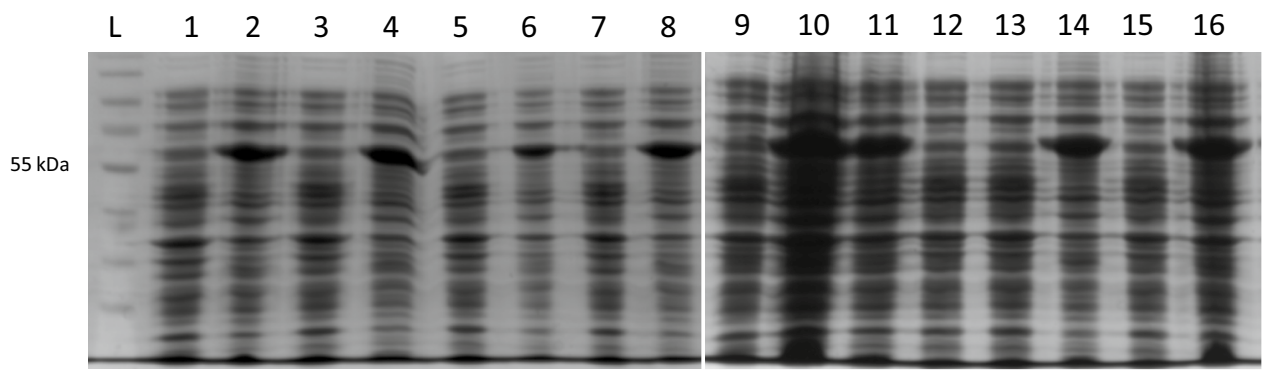

Fig. 4 Selection of overexpressing colonies after 2 rounds of induction with IPTG. The second round of selected colonies overexpressing VP2-P8 (lanes 1-8) and VP2-249 (lanes 9-16) is shown. Lanes L: Ladder, 1: colony 1 VP2-P8 pre induction, 2: colony 1 VP2-P8 post induction, 3: colony 2 VP2-P8 pre induction, 4: colony 2 VP2$\mathrm{P} 8$ post induction, 5: colony $3 \mathrm{VP} 2-\mathrm{P} 8$ pre induction, 6: colony 3

The production of chimeric proteins and VP2 was scaled up by growing the colonies in $200 \mathrm{~mL}$ of a combined medium $\mathrm{LB}+\mathrm{TB}$, for $16 \mathrm{~h}$ at $30{ }^{\circ} \mathrm{C}$, with stirring at 200 RPM and extracted by sonication (see materials and methods). Thereafter, VP2 chimeric proteins and VP2 were purified by nickel-IMAC and eluted in 1-mL fractions.

Subsequently, each of the eluted fractions, as well as unbound protein fractions and pre-elution void volume, was analysed by SDS-PAGE and stained with Coomassie blue dye. Figure 5 shows the fractions obtained from each of the elutions for VP2 and each of the chimeras.

We can observe that for both VP2 and VP2-249, the majority of the protein is found in fractions 1 and 2 , and for VP2-P8, it is eluted in fractions 1, 6 and 7. Therefore, these fractions were concentrated by centrifugation in filtration
VP2-P8 post induction, 7: colony 4 VP2-P8 pre induction, 8: colony 4 VP2-P8 post induction, 9: colony 1 VP2-249 pre induction, 10: colony 1 VP2 -249 post induction, 11: colony 2 VP2-249 post induction, 12: colony 2 VP2-249 pre induction, 13: colony 3 VP2-249 pre induction, 14: colony 3 VP2-249 post induction, 15: colony 4 VP2 -249 pre induction and 16: colony 4 VP2-249 post induction

units (Millipore, MA, USA) with an exclusion MWCO of $30 \mathrm{kDa}$ to be subsequently quantified by the Bradford method against known concentrations of bovine serum albu$\min (\mathrm{BSA})(100 \mathrm{ng}-10 \mu \mathrm{g})$. The protein yield for VP2, VP2249 and VP2-P8 was $\sim 60 \mathrm{mg} / \mathrm{L}$.

\section{VLP Assembly}

The next step was the assembly of VLPs from VP2, the single chimeras and a mixture of chimeras in a 1:1 ratio (hybrid P8/249). The assembly of VLPs was carried out by dialysis of $1 \mathrm{~mL}$ of the recombinant protein $(0.75 \mathrm{mg} / \mathrm{mL}$ in Solubilization Buffer) against $50 \mathrm{~mL}$ of PBS pH 7.4 supplemented with $0.25 \mathrm{M}$ of L-Arg at $4{ }^{\circ} \mathrm{C}$, changing the buffer every $12 \mathrm{~h}$ during a period of $72 \mathrm{~h}$ [24]. For the assembly of 
VP2

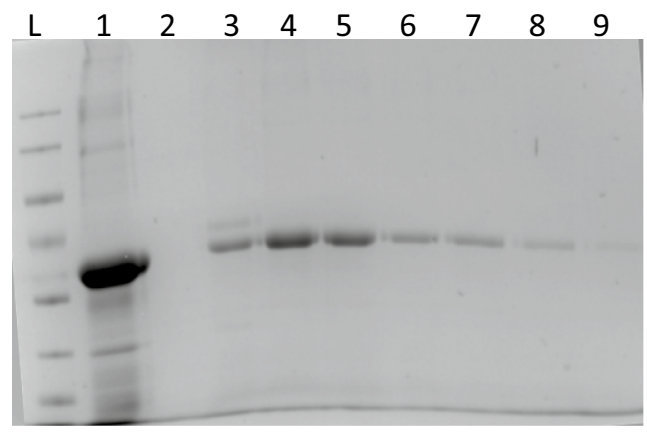

VP2-249

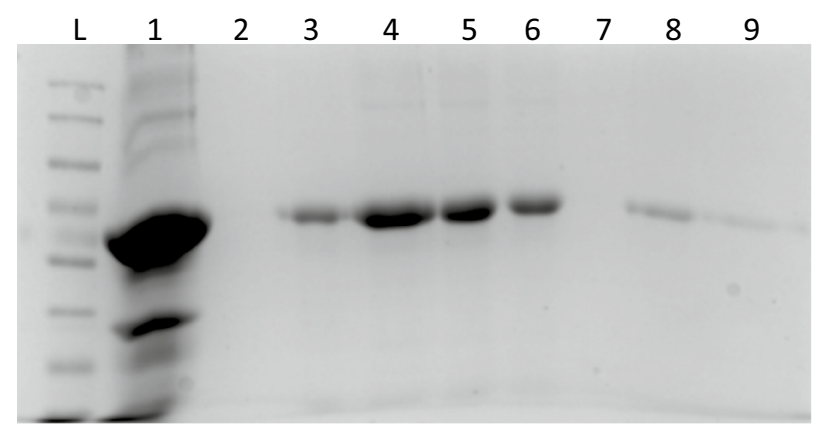

VP2-P8

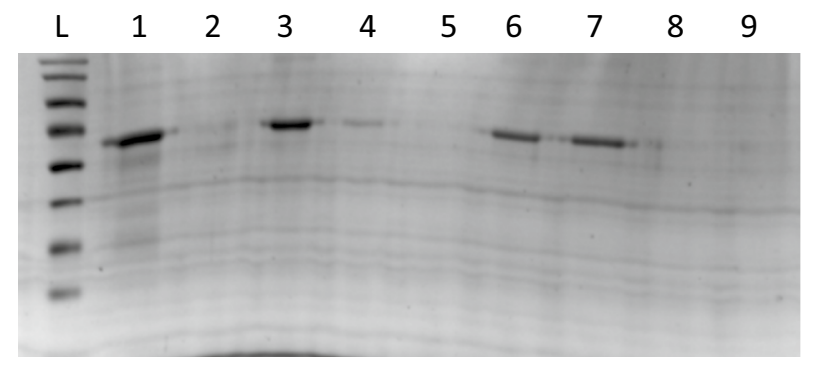

Fig. 5 SDS-PAGE of fractions eluted from native VP2 and their chimeras. After nickel column purification, dialysis against 8 Murea of $25 \mu \mathrm{L}$ of each of the obtained fractions was carried out for subsequent analysis by SDS-PAGE. Lanes, L: Ladder, 1: solubilized, 2: N, 3: P, 4-9: elutions 1-6

hybrid particles of VP2-249 and VP2-P8, the final protein concentration was maintained at $0.750 \mathrm{mg} / \mathrm{mL}$. The epitopes for both P8 and 249 represent the $2.72 \%$ of the chimera; therefore, $20.4 \mu \mathrm{g}$ of both epitopes are present in the total chimeras; this value can be relevant for further dosage evaluations prior to immunization.

After assembly, the particle size was characterized as well as the percentage of protein assembled by DLS. The results are shown in Fig. 6. Previous reports of assembly of VP2 VLPs show an approximate diameter of 20-25 nm $[22,25]$. The summarized results are shown in Table 1 .
All VLPs assembled were of the previously reported size, and the polydispersity index (PDI) $<0.4$ indicated a nearly monodisperse sample, along with $>99.9 \%$ of the sample of the respective desired VLPs. It is worth mentioning that DLS results are often expressed in terms of the Z-average. The Z-average arises when DLS data are analysed by using the technique of cumulants. Since the calculation of the $\mathrm{Z}$-average is mathematically stable, the $\mathrm{Z}$-average result is insensitive to noise and provides a reliable measure of the average particle size in a distribution [26].

\section{Chimeric VLPs Protected Mice Against 4T1 Tumour Induction}

As a prophylactic approach to induce tumour immunity, assembled chimeric VLPs were administered to female BALB/c mice. Mice were divided into groups (mentioned above) and 4 weekly intraperitoneal immunizations with $100 \mu \mathrm{g}$ of VLPs protected mice from tumour formation and growth in a 4T1 cell-administered model.

After 30 days post inoculation with the $4 \mathrm{~T} 1$ cancer cell line, mice immunized with hybrid P8/249 VLPs in a 1:1 ratio, 249 VLPs and native VP2 VLPs did not develop detectable tumours. Moreover, when mice were euthanized at the end of the experiment, no signs of metastasis or solid tumours were present in these groups. Only one mouse of the P8 VLP-immunized group presented a small tumour of $113.8 \mathrm{~mm}^{3}$ in contrast with the $441.87 \pm 120.38 \mathrm{~mm}^{3}$ tumours presented by the mice in the PBS group (Fig. 7).

\section{Humoral and Cellular Responses of Mice Immunized with Chimeric VLPs}

After the immunization scheme (day $x$ ), ELISA assays targeting either P8 or 249 synthetic peptides or native VP2 with sera from immunized mice revealed that the groups immunized with hybrid P8/249 VLPs elicited specific IgG against VP2 and P8, and P8 VLPs elicited specific P8 antibodies. As expected, specific VP2 antibodies were detected in all immunized groups (Fig. 8).

To analyse the cellular response, spleen lymphocytes of immunized mice were stimulated for $72 \mathrm{~h}$ in vitro with P8 or 249 synthetic peptides or native VP2. Flow cytometry analysis showed a decrement in the amount of CD3+ lymphocytes in the PBS group that developed tumours. In contrast, the vaccinated VLPs groups, which were protected against tumour growth, showed normal percentages of T cells. Also, the mice that presented smaller tumours than the ones in the PBS group presented a minor diminution in the proportion of CD3+ lymphocytes (Fig. 9a). The proportion of the CD4+ and CD8+ cell populations was not changed with either immunization treatment compared with healthy, unvaccinated and nontumour-inoculated mice. (Figure 9b). No significant CD4+ and 
A $\begin{aligned} \text { Z-Average (d.nm): } & 26.75 \\ \text { Pdl: } & 0.367 \\ \text { Intercept: } & 0.526\end{aligned}$ Result quality : Good

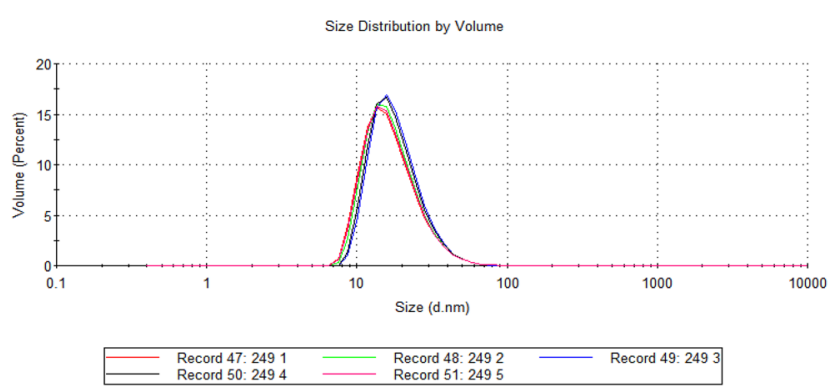

C

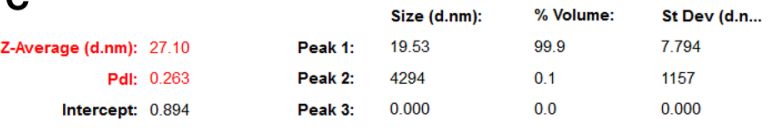

Result quality: Good
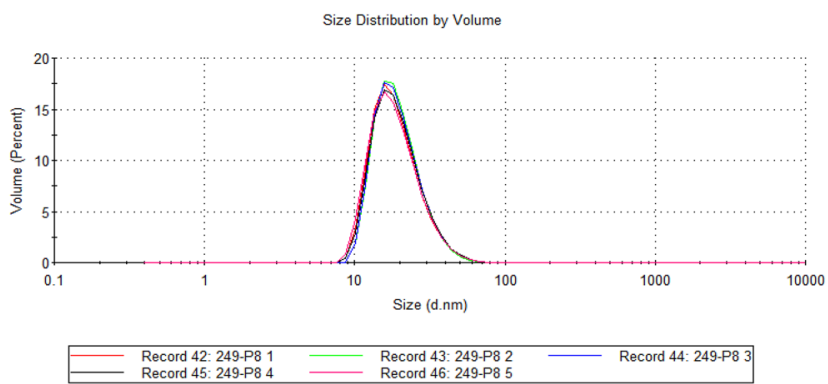

Fig. 6 DLS analysis. Self-assembled VLPs from VP2-249 (a), VP2P8 (b), hybrid 249/P8 (c) and native VP2 (d) were analysed under dynamic light dispersion, and the range of fully assembled VLPs was

Table 1 Dynamic light scattering (DLS) data results

\begin{tabular}{lllll}
\hline Sample & $Z$-average (d.nm) & size (d.nm) & $\%$ volume & PDI \\
\hline 249-VLPs & 26.75 & 17.74 & 99.9 & 0.367 \\
P8-VLPs & 26.38 & 19.39 & 100 & 0.204 \\
249/P8-VLPs & 27.1 & 19.53 & 99.9 & 0.263 \\
VP2-VLPs & 24.94 & 18.69 & 100 & 0.227 \\
\hline
\end{tabular}

CD8+ cell proliferative responses in the presence of specific stimulus (Fig. 10a, b) were detected. This may suggest that the antitumoural effect elicited does not depend on the induction of a specific $\mathrm{CD} 3$ response, but further evaluation of the cellular responses with other methodologies remains to be done.
B

\begin{tabular}{|c|c|c|c|c|c|}
\hline & & & Size (d.nm): & \% Volume: & St Dev (d.n... \\
\hline Z-Average (d.nm): & 26.38 & Peak 1: & 19.39 & 100.0 & 8.360 \\
\hline Pdl: & 0.204 & Peak 2: & 0.000 & 0.0 & 0.000 \\
\hline Intercept: & 0.587 & Peak 3: & 0.000 & 0.0 & 0.000 \\
\hline
\end{tabular}

Result quality: Good
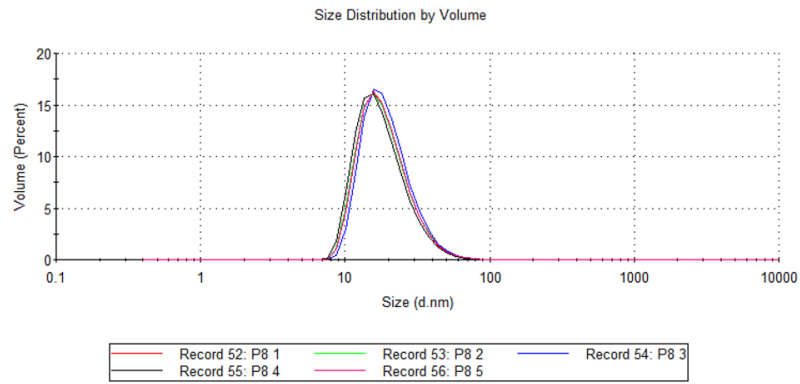

D

$\begin{array}{rlllll}\text { Z-Average (d.nm): } 24.94 & & & \text { Size (d.nm): } & \text { \% Volume: } & \text { St Dev (d.n... } \\ \text { Pdl: }: 0.227 & \text { Peak 1: } & 18.69 & 100.0 & 7.998 \\ \text { Intercept: } & 0.897 & \text { Peak 3: } & 0.000 & 0.0 & 0.000 \\ & & & & 0.000 & 0.000\end{array}$

Result quality : Good

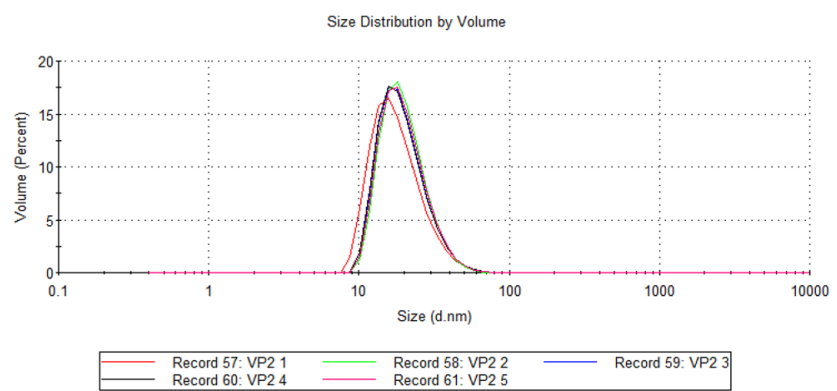

between 20 and $25 \mathrm{~nm}$ in diameter (d.nm). This demonstrates that native VP2 VLPs and chimeric VLPs fully self-assembled

\section{Antitumoral efect of VLPs}

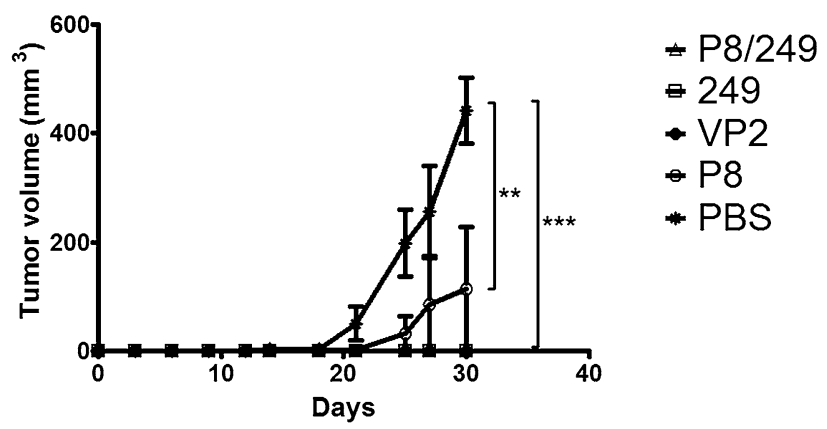

Fig. 7 Antitumoural effect of VLPs. Prophylactic antitumoural effect of immunization with VLPs was determined measuring tumour volume for 30 days post injection with 4T1 cells. Mice were immunized weekly with different treatments of VLPs or received vehicle PBS. On day 35, all groups were injected with 4T1 cells. All mice from the PBS group presented tumours (mean size $441.87 \pm 120.38 \mathrm{~mm}^{3}$ ), in contrast to hybrid P8/249, 249 and VP2 groups, which showed no tumour development, and only one mouse from group P8 presented a reduced tumour after 30 days $113.8 \mathrm{~mm}^{3}$. *** $P<0.01$; *** $P<0.001$ 


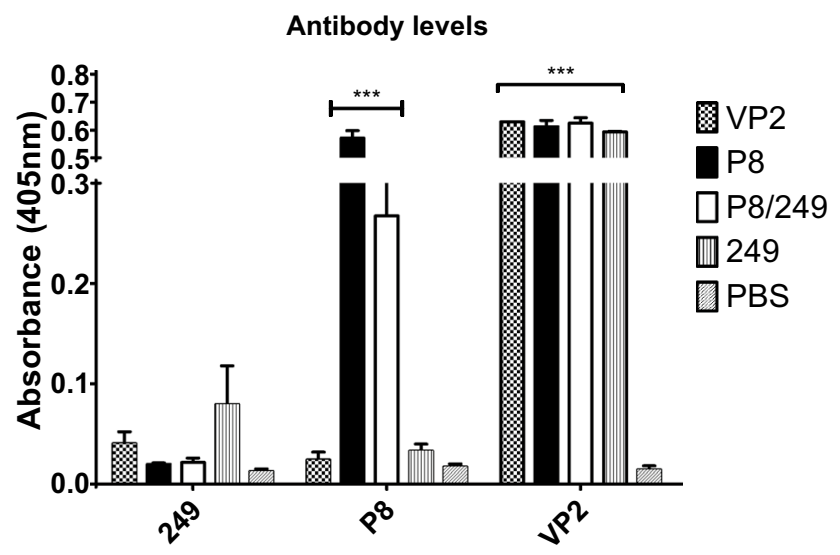

Fig. 8 Immunization with VLPs induces specific antibody responses. On day 29, after 4 immunizations with treatments, blood was extracted by tail vein bleeding to obtain sera from mice. Specific P8, P249 or VP2 antibodies were determined by ELISA in the sera of immunized mice before injection with $4 \mathrm{~T} 1$ cells. At a 1:10 dilution, specific anti-P8 antibodies were detected by ELISA in the sera of mice immunized with P8-VLPs and hybrid P8/249 VLPs, and specific anti-VP2 antibodies were detected in mice immunized with native VLPs, P8-VLPs, hybrid P8/249 VLPs and 249-VLPs. *** $P<0.001$

\section{Discussion}

The IGF-1R plays a key role in proliferation, cellular growth and antiapoptotic activity [27], and it has been reported that this receptor is overexpressed in several cancer types, including breast, colorectal and lung cancers, urothelial carcinoma and pancreatic adenocarcinoma, among others. IGF-1R has the potential to be an attractive target due to the possibility of inhibiting tumour growth in cells resistant to chemotherapy and anti-hormonal therapy [28].

Herein, we demonstrated that IGF-1R epitopes displayed in chimeric VP2 B19V-based VLPs can be expressed, purified easily and assembled in VLPs in a proof of concept of a multiepitope vaccine against cancer.

Keeping in mind that this approach will allow the generation of a library of VP2 with any epitope of interest and the subsequent assembly of VLPs with the desired epitopes in order to obtain versatile and personalized VLPs against cancer, this approach was aimed against breast cancer, but we can express desired epitopes of any kind for assembly under feasible conditions.

This preliminary evaluation of the potential of chimeric VP2 with IGF-1R epitopes assembled in VLPs to induce tumour immunity indicates their value, as a decrease or absence of tumour growth was attained in all vaccinated groups: in contrast to the PBS group, all four mice presented a mean tumour growth of $441.87 \mathrm{~mm}^{3}$, and only one P8-VLP-immunized mouse presented a small tumour of $113.8 \mathrm{~mm}^{3}$. It has been reported that breast cancer induces a decrement in total CD3+ cells; this was consistent with our results [29], but the vaccinated groups did not show a decrease in this cell population, and even the mouse in the P8 group with a tumour recovered CD3+ levels similar to those of the unvaccinated and non-inoculated control. This decrement could also be due to the aberrant zeta chain$\mathrm{CD} 3+$ that has been reported in cancer patients [30, 31].

Results demonstrated in this preliminary study suggest an important role of antibodies in the antitumoural effect of candidate vaccines. It is important to clarify that the P8 epitope is a B-cell epitope; therefore, only mice immunized with hybrid VLP and P8 VLP sera react against the P8 epitope and not the 249 epitope. The same was true in the proliferation assay, where the 249 epitope, a T-cell epitope, induced a CD3+ cellular response, but in this preliminary study, we were unable to detect significant specific proliferative responses after re-stimulation with a specific peptide. Although this suggests that the antitumoural effect does not depend on the cellular response, further evaluation of the participation of the cellular immune response remains to be done.

It is worth mentioning that in this preliminary study, native VP2 VLP-immunized mice also exhibit an absence of tumours, even without the inclusion of IGF-1R epitopes. A possible explanation of this effect could be that it is due to blockage of $\alpha 5 \beta 1$ integrin, as B 19V VP2 has been reported to bind to this integrin which functions as an adhesion molecule expressed by endothelial cells, smooth muscle cells and cellular components of the blood, such as platelets, monocytes and lymphocytes [32, 33]. Moreover, this $\alpha 5 \beta 1$ integrin has a critical role in physiological angiogenesis, as knockout mice for this integrin show vascular abnormalities [34-36]. Also, $\alpha 5 \beta 1$ integrin has been reported to be overexpressed in solid tumours (colon, ovarium, breast, lung, glioma, melanoma) [37], and the search for specific $\alpha 5 \beta 1$ integrin antagonists to be used as tumour targets has been increased in recent years [38]. Specifically, by using SC immunization as we did, direct competition between the VP2 core of chimeric and native VLPs and the $\alpha 5 \beta 1$ integrin could be achieved. Thus, our VP2-based VLPs expressing TAAs are a convenient delivery system for candidate vaccines against solid tumours.

Further experiments with this approach will lead to a much deeper analysis of our candidates; since P8-VLPs, 249-VLPs, hybrid-P8/249 VLPs and also native VP2 VLPs decreased or inhibited tumour growth in this preliminary study, we will aim our efforts at elucidating the mechanism behind this antitumoural effect. Also, even though the reported epitopes do not share identity with the insulin receptor [8], targeting an insulin-like receptor can lead to a hypoglycaemic effect that will also be examined in further studies. 

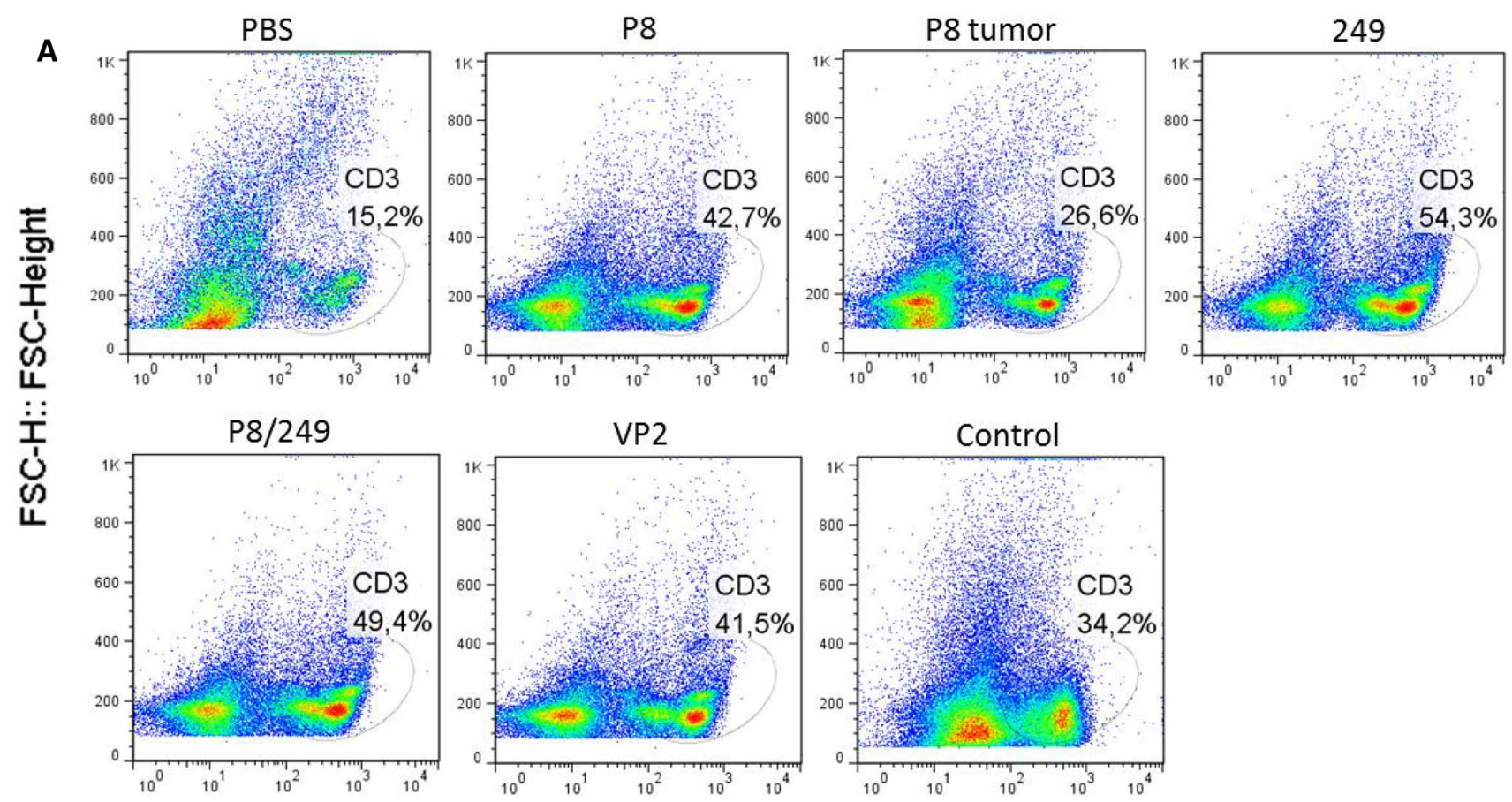

FL4-H:: CD3 APC

B
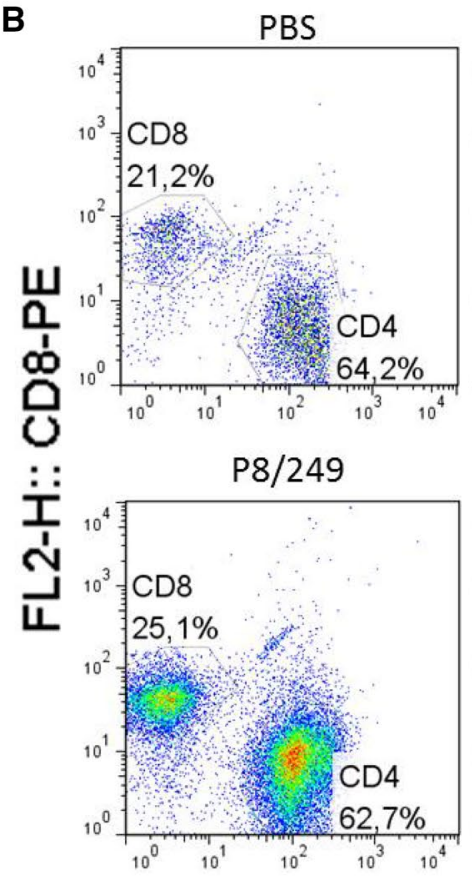

P8

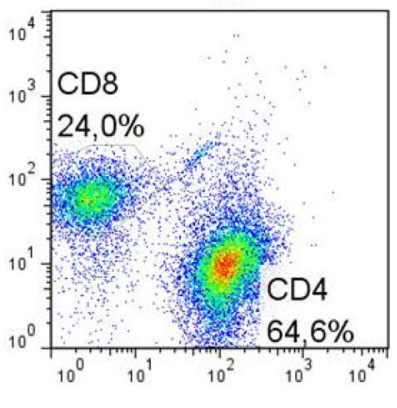

VP2

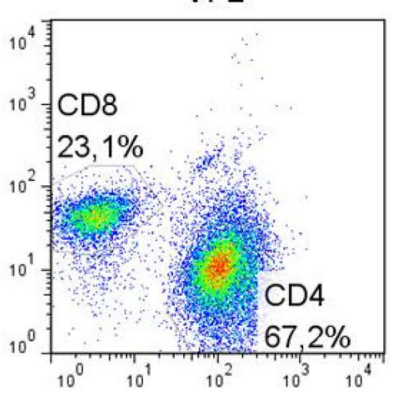

P8 tumor
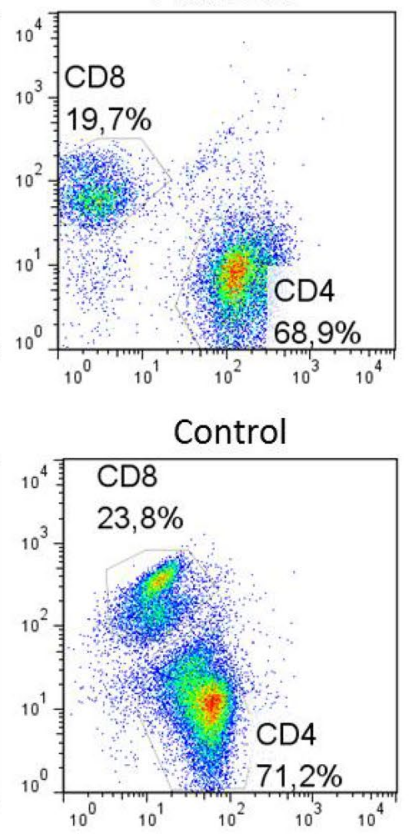

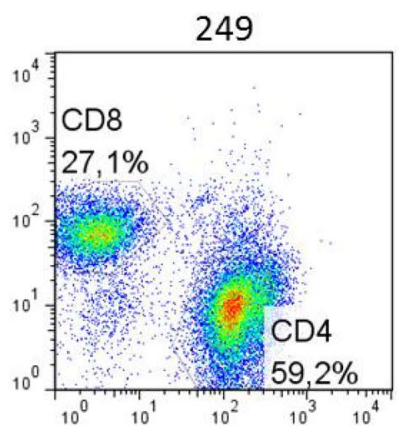

FL3-H:: CD4-Cy5PE

Fig. 9 Flow cytometry analysis of total CD3+ lymphocytes. After isolation of spleenocytes, CD3+ lymphocytes were measured, and a decrease in the total amount of CD3+ cells could be observed in the PBS group compared with the increase in these populations in immunized groups. An increase in this population of cells in a mouse in the P8 group which presented a reduced tumour was observed. An unvaccinated mouse not administered 4T1 cells was used as a healthy control (a). Even with a reduction of $\mathrm{CD} 3+$ in the PBS group, the proportion of CD4+ and CD8+ cells was the same in the control PBS group and groups administered native VLPs, P8-VLPs, hybrid P8/249 VLPs and 249-VLPs. An unvaccinated mouse not administered 4T1 cells was used as a healthy control (b) 


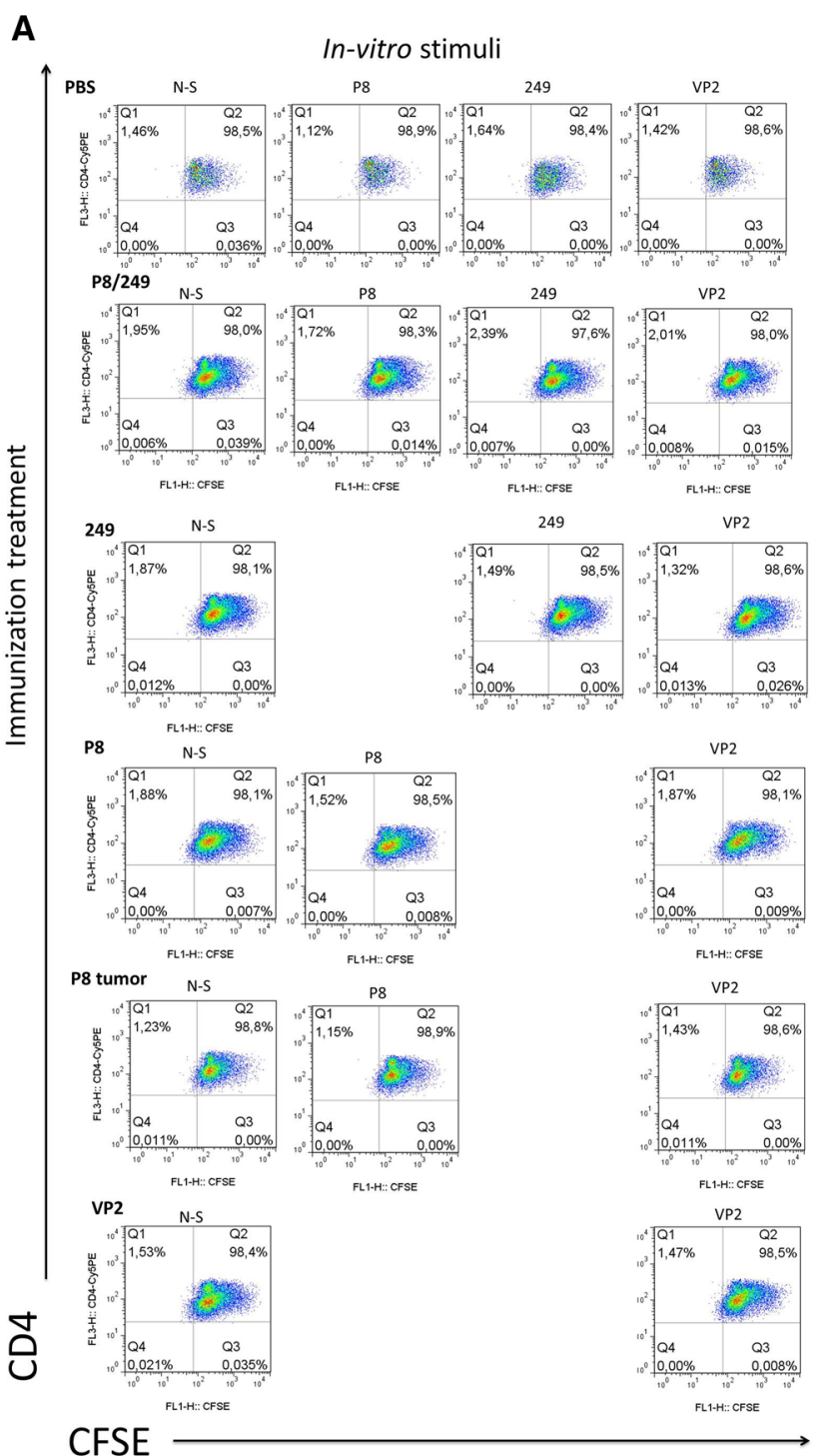

Fig. 10 Evaluation of proliferation of CD4+ and CD8+ T cells in the presence of specific stimuli. In vitro proliferation was determined after $72 \mathrm{~h}$ of stimulation with either P8 or 249 peptides or native VP2 and compared with the proliferation of unstimulated cells (N-S). Rep-

Acknowledgement This work was supported by CONACYT CB283319 and UNAM PAPIIT IN223319. J.A. Salazar-González is a postdoctoral fellow and received a UNAM DGAPA scholarship. Thanks to Damaris Ilhuicatzi Alvarado for the technical support.

\section{References}

1. Chakraborty, S., \& Rahman, T. (2012). The difficulties in cancer treatment. Ecancermedicalscience, 6, 16. https://doi.org/10.3332/ ecancer.2012.ed16.

2. Maeda, H., \& Khatami, M. (2018). Analyses of repeated failures in cancer therapy for solid tumors: poor tumor-selective drug delivery, low therapeutic efficacy and unsustainable costs. Clinical

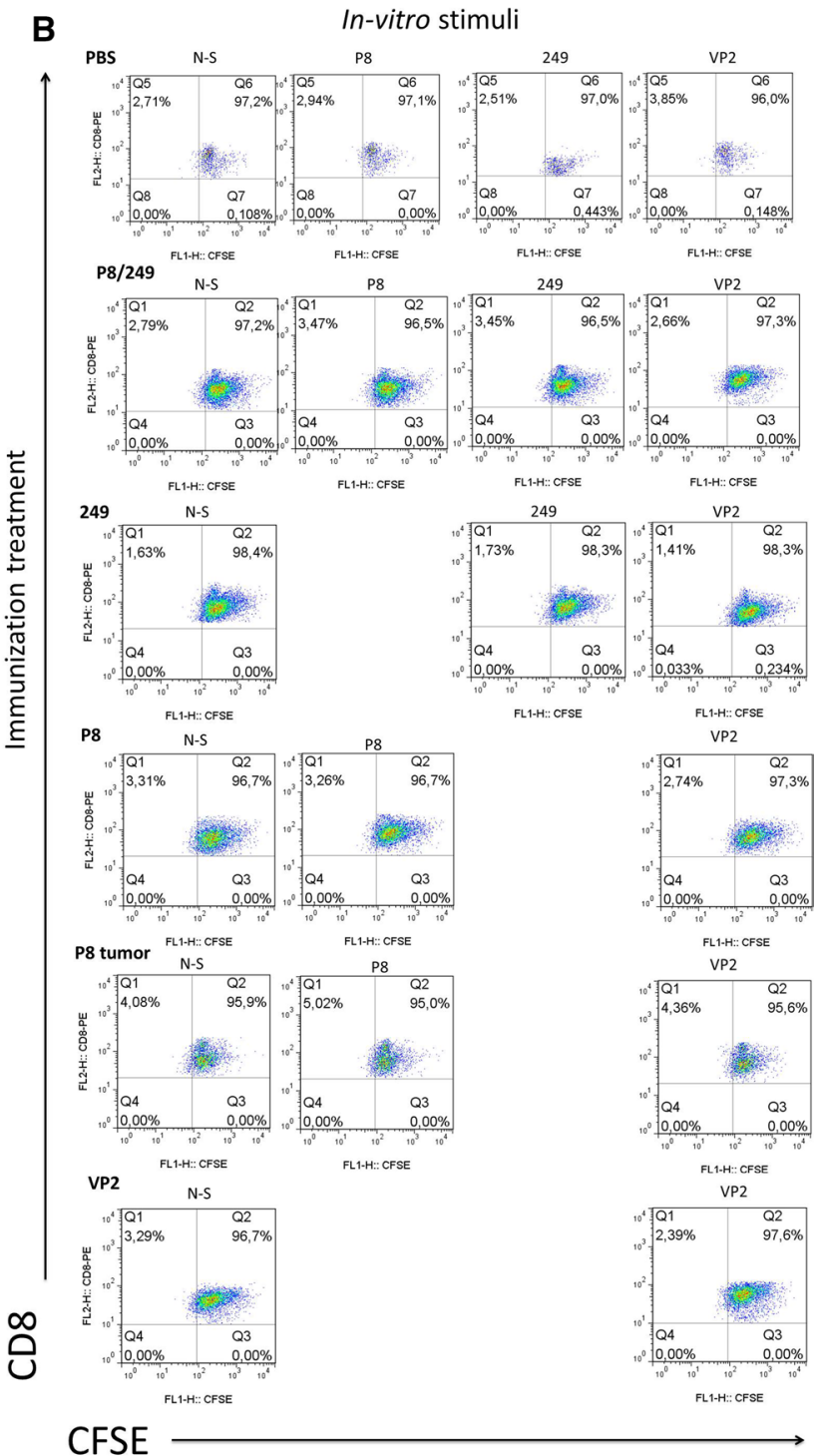

resentative dot plots from each group are shown. No increase in specific proliferation was observed due to the immunization treatments after stimulation with the specific treatments for $72 \mathrm{~h}$ in $\mathrm{CD} 4+$ (a) and CD8+ (b) cells

and Translational Medicine, 7, 11. https://doi.org/10.1186/s4016 9-018-0185-6.

3. Nahta, R., Yu, D., Hung, M. C., Hortobagyi, G. N., \& Esteva, F. J. (2006). Mechanisms of disease: understanding resistance to HER2-targeted therapy in human breast cancer. Nature Clinical Practice Oncology, 3, 269-280.

4. Farabaugh, S. M., Boone, D. N., \& Lee, A. V. (2015). Role of IGF1R in breast cancer subtypes, stemness, and lineage differentiation. Frontiers in Endocrinology (Lausanne), 6, 59.

5. Coskun, U., Gunel, N., Sancak, B., Gunel, U., Onuk, E., Bayram, O., et al. (2003). Significance of serum vascular endothelial growth factor, insulin-like growth factor-I levels and nitric oxide activity in breast cancer patients. Breast, 12, 104-110.

6. Reinmuth, N., Fan, F., Liu, W., Parikh, A. A., Stoeltzing, O., Jung, Y. D., et al. (2002). Impact of insulin-like growth factor receptor-I 
function on angiogenesis, growth, and metastasis of colon cancer. Laboratory Investigation, 82, 1377-1389.

7. Stoeltzing, O., Liu, W., Reinmuth, N., Fan, F., Parikh, A. A., Bucana, C. D., et al. (2003). Regulation of hypoxia-inducible factor-1alpha, vascular endothelial growth factor, and angiogenesis by an insulin-like growth factor-I receptor autocrine loop in human pancreatic cancer. American Journal of Pathology, 163, 1001-1011.

8. Bayrami, V., Keyhanfar, M., Mohabatkar, H., Mahdavi, M., \& Moreau, V. (2016). In silico prediction of B cell epitopes of the extracellular domain of insulin-like growth factor-1 receptor. Molecular Biology Research Communications, 5(4), 201-214.

9. Mahdavi, M., Moreau, V., \& Kheirollahi, M. (2017). Identification of B and T cell epitope based peptide vaccine from IGF-1 receptor in breast cancer. Journal of Molecular Graphics and Modelling, 75, 316-321.

10. Dougan, M., \& Dranoff, G. (2009). Immune therapy for cancer. Annual Review of Immunology, 27, 83-117.

11. Fuenmayora, J., Gòdiaa, F., \& Cervera, L. (2017). Production of virus-like particles for vaccines. New Biotechnology, 39(Pt B), 174-180. https://doi.org/10.1016/j.nbt.2017.07.010.

12. Huang, X., Wang, X., Zhang, J., Xia, N., \& Zhao, Q. (2017). Escherichia coli-derived virus-like particles in vaccine development. NPJ Vaccines, 2, 3. https://doi.org/10.1038/s4154 1-017-0006-8.

13. Roldão, A., Mellado, M. C., Castilho, L. R., Carrondo, M. J., \& Alves, P. M. (2010). Virus-like particles in vaccine development. Expert Review of Vaccines, 9(10), 1149-1176. https://doi. org/10.1586/erv.10.115.

14. Bachmann, M. F., Rohrer, U. H., Kündig, T. M., Bürki, K., Hengartner, H., \& Zinkernagel, R. M. (1993). The influence of antigen organization on B cell responsiveness. Science, 262, 1448-1451.

15. Ruedl, C., Schwarz, K., Jegerlehner, A., Storni, T., Manolova, V., \& Bachmann, M. F. (2005). Virus-like particles as carriers for T-cell epitopes: Limited inhibition of T-cell priming by carrierspecific antibodies. Journal of Virology, 79, 717-724.

16. Keller, S. A., Schwarz, K., Manolova, V., von Allmen, C. E., Kinzler, M. G., Bauer, M., et al. (2010). Innate signaling regulates cross-priming at the level of DC licensing and not antigen presentation. European Journal of Immunology, 40, 103-112.

17. Grgacic, E. V., \& Anderson, D. A. (2006). Virus-like particles: Passport to immune recognition. Methods, 40, 60-65.

18. Kushnir, N., Streatfield, S. J., \& Yusibov, V. (2012). Virus-like particles as a highly efficient vaccine platform: Diversity of targets and production systems and advances in clinical development. Vaccine, 31, 58-83.

19. Bachmann, M. F., \& Jennings, J. T. (2010). Vaccine delivery: A matter of size, geometry, kinetics and molecular patterns. Nature Reviews Immunology, 10, 787-796.

20. Chen, Q., \& Lai, H. (2013). Plant-derived virus-like particles as vaccines. Human Vaccines \& Immunotherapeutics, 9, 26-49.

21. Sánchez-Rodríguez, S. P., Münch-Anguiano, L., Echeverría, O., Vázquez-Nin, G., Mora-Pale, M., Dordick, J. S., et al. (2012). Human parvovirus B19 virus-like particles: In vitro assembly and stability. Biochimie, 94, 870-878.

22. Bustos-Jaimes, I., Soto-Román, R. A., Gutiérrez-Landa, I. A., Valadez-García, J., \& Segovia-Trinidad, C. L. (2017). Construction of protein-functionalized virus-like particles of parvovirus B19. Journal of Biotechnology, 263, 55-63.

23. Bailey-Downs, L. C., Thorpe, J. E., Disch, B. C., Bastian, A., Hauser, P. J., Farasyn, T., et al. (2014). Development and characterization of a preclinical model of breast cancer lung micrometastatic to macrometastatic progression. PLoS ONE, 9(5), e98624. https://doi.org/10.1371/journal.pone.0098624.
24. Sánchez-Rodríguez, S. P., Morán-García, A. C., Bolonduro, O., Dordick, J. S., \& Bustos-Jaimes, I. (2016). Enhanced assembly and colloidal stabilization of primate erythroparvovirus 1 viruslike particles for improved surface engineering. Acta Biomaterialia, 35, 206-214.

25. Morán-García, A. C., Rivera-Toledo, E., Echeverría, O., VázquezNin, G., Gómez, B., \& Bustos-Jaimes, I. (2016). Peptide presentation on primate erythroparvovirus 1 virus-like particles: In vitro assembly, stability and immunological properties. Virus Research, 224, 12-18.

26. Koppel, D. E. (1972). Analysis of macromolecular polydispersity in intensity correlation spectroscopy: The method of cumulants. The Journal of Chemical Physics, 57, 4814-4820.

27. Baserga, R., Peruzzi, F., \& Reiss, K. (2003). The IGF-1 receptor in cancer biology. International Journal of Cancer, 107, 873-877.

28. Cox, O. T., O'Shea, S., Tresse, E., Bustamante-Garrido, M., Kiran-Deevi, R., \& O'Connor, R. (2015). IGF-1 Receptor and adhesion signaling: An important axis in determining cancer cell phenotype and therapy resistance. Frontiers in Endocrinology (Lausanne), 6, 106.

29. Murta, E. F., de Andrade, J. M., Falcão, R. P., \& Bighetti, S. (2000). Lymphocyte subpopulations in patients with advanced breast cancer submitted to neoadjuvant chemotherapy. Tumori, $86,403-407$.

30. Farace, F., Angevin, E., Vanderplancke, J., Escudier, B., \& Triebel, F. (1994). The decreased expression of CD3 zeta chains in cancer patients is not reversed by IL-2 administration. International Journal of Cancer, 59, 752-755.

31. Yu, B., \& Zhang, W. (2011). Down-regulation of CD3zeta is a breast cancer biomarker associated with immune suppression. Cell Biology International, 35, 165-169.

32. Avraamides, C. J., Garmy-Susini, B., \& Varner, J. A. (2008). Integrins in angiogenesis and lymphangiogenesis. Nature Reviews Cancer, 8, 604-617.

33. Weigel-Kelley, K. A., Yoder, M. C., \& Srivastava, A. (2003). Alpha5beta1 integrin as a cellular coreceptor for human parvovirus B19: requirement of functional activation of beta1 integrin for viral entry. Blood, 102, 3927-3933.

34. Bader, B. L., Rayburn, H., Crowley, D., \& Hynes, R. O. (1998). Extensive vasculogenesis, angiogenesis, and organogenesis precede lethality in mice lacking all alpha v integrins. Cell, 95, 507-519.

35. Carlson, T. R., Hu, H., Braren, R., Kim, Y. H., \& Wang, R. A. (2008). Cell-autonomous requirement for beta1 integrin in endothelial cell adhesion, migration and survival during angiogenesis in mice. Development, 135, 2193-2202.

36. Li, L., Welser-Alves, J., van der Flier, A., Boroujerdi, A., Hynes, R. O., \& Milner, R. (2012). An angiogenic role for the alpha5beta1 integrin in promoting endothelial cell proliferation during cerebral hypoxia. Experimental Neurology, 237, 46-54.

37. Schaffner, F., Ray, A. M., \& Dontenwill, M. (2013). Integrin $\alpha 5 \beta 1$, the fibronectin receptor, as a pertinent therapeutic target in solid tumours. Cancers (Basel), 5, 27-47.

38. Goodman, S. L., \& Picard, M. (2012). Integrins as therapeutic targets. Trends in Pharmacological Sciences, 33, 405-412.

Publisher's Note Springer Nature remains neutral with regard to jurisdictional claims in published maps and institutional affiliations. 